\title{
An audit of radiographers' practice of left- right image annotation in film-screen radiography and after installation of computed radiography in a tertiary hospital in Africa
}

Thomas Adejoh ${ }^{1 *}$, Chukwuemeka H. Elugwu' ${ }^{1}$, Mohammed Sidi ${ }^{2}$, Emeka E. Ezugwu ${ }^{3}$, Chijioke O. Asogwa ${ }^{3}$ and Mark C. Okeji ${ }^{4}$

\begin{abstract}
Background: Errors in radiographic image annotation by radiographers could potentially lead to misdiagnoses by radiologists and wrong side surgery by surgeons. Such medical negligence has dire medico-legal consequences. It was hypothesized that newer technology of computed radiography (CR) and direct digital radiography (DDR) image annotation would potentially lead to a change in practice with subsequent reduction in annotation errors. Following installation of computed radiography, a modality with electronic, post-processing image annotation, the hypothesis was investigated in our study centre.

Results: A total of 72,602 and 126,482 images were documented for film-screen radiography (FSR) and computed radiography (CR), respectively in the department. From these, a sample size of 9452 made up of 4726 each for FSR and CR was drawn. Anatomical side marker errors were common in every anatomy imaged, with more errors seen in FSR (4.6\%) than CR (0.6\%). Collectively, an error rate of 3.0\% was observed. Errors noticed were as a result of marker burnout due to over-exposure as well as marker cone off due to tight beam collimation.

Conclusion: Error rates were considerably reduced following a change from film-screen radiography (FSR) to computed radiography (CR) at the study centre. This change was, however, influenced more by a team of quality control radiographers stationed at CR workstation than by actual practice in x-ray imaging suite. Presence of anthropomorphic phantom in the teaching laboratories in the universities for demonstrations will significantly inculcate the skill needed to completely eliminate anatomical side marker (ASM) error in practice.
\end{abstract}

Keywords: Anatomical side markers, Radiographs, Radiographers, Film-screen radiography, Computed radiography

\footnotetext{
*Correspondence: t.adejoh@gregoryuniversityuturu.edu.ng;

adtoms@yahoo.com

'Department of Radiography \& Radiation Sciences, Gregory University, Uturu,

Abia State, Nigeria

Full list of author information is available at the end of the article
}

\section{Springer Open}

(c) The Author(s). 2020 Open Access This article is licensed under a Creative Commons Attribution 4.0 International License, which permits use, sharing, adaptation, distribution and reproduction in any medium or format, as long as you give appropriate credit to the original author(s) and the source, provide a link to the Creative Commons licence, and indicate if changes were made. The images or other third party material in this article are included in the article's Creative Commons licence, unless indicated otherwise in a credit line to the material. If material is not included in the article's Creative Commons licence and your intended use is not permitted by statutory regulation or exceeds the permitted use, you will need to obtain permission directly from the copyright holder. To view a copy of this licence, visit http://creativecommons.org/licenses/by/4.0/. 


\section{Background}

Radiographic image annotation is a core skill inculcated in every radiographer from the classroom to the clinic. It is a fundamental evidence of acceptable technique [1]. In abnormality detection on radiographs by radiographers, image annotation is a core feature to watch out for [2]. The most popular annotation method is an indication of 'left' and 'right' using anatomical side marker (ASM), a portable radiopaque object in the shape of letter ' $U$ ' with a void capital ' $L$ ' and ' $R$ ' carved on alternate rami [3]. The ' $U$ ' shape is to create a loop for attachment to image detector casings [4]. Anatomical side markers (ASMs) are used in imaging every patient and are amongst the most frequently handled objects in the radiology department [5].

Annotation of radiographic images is radiographerdependent and therefore, subject to human error [6]. In medical practice, negligence is however not justifiable [3]. It has been noted that in routine, as well as in forensic radiography, ASMs must be included on the image to be admitted as a legal document. It was also reported that absence of ASM is a strong risk factor for misdiagnosis by radiologists, as well as wrong side surgery by surgeons, with attendant medico-legal and fatal consequences [7, 8]. Faintly-labeled, mislabeled and nonlabeled images are deemed as errors in image annotation. Although legible anatomical side markers in the penumbra of $\mathrm{x}$-ray beam are not errors, they are considered not to be best practices [4].

Opinions are divided as to whether ASMs should appear in umbra or penumbra of the x-ray beam [3]. By tradition passed down and which remains current popular practice, umbra is favoured to prevent cone off $[1,9]$. However, this practice has the tendency for marker burn-out during overexposure and as well as masking of essential anatomy. Legibility and sparing of essential anatomy are therefore suggested as key criteria for marker location. Adejoh et al. (2014) [4] reported that aesthetics and increased distance from useful anatomy were the major reasons ASMs are placed towards the right angles of images.

In our study centre, an unpublished pilot survey by the head of the unit in 2013 revealed that $2 \%$ of radiographs had marker error. To mitigate that, every radiographer was required to own a personal ASM rather than depend on the departmental supply. The head of the unit, in addition, assigned three radiographers to the image quality control desk. A year later (2014), computed radiography (CR) was installed to replace conventional film-screen radiography (FSR). It was hypothesized that electronic annotation of images will reduce ASM errors [1]. This work was aimed at auditing the practice of image annotation by radiographers after the introduction of $\mathrm{CR}$ and other measures introduced to mitigate the marker errors. Two major standards for ASM audits are (i) presence or absence of markers on images [3], and (ii) presence of marker in primary or secondary radiation beam [1,9]. This work adopted presence or absence of marker, irrespective of whether they appear in primary or secondary radiation field, as standard. However, location of markers within radiation beam as well as specific sources of errors, although not adopted as standards, were also noted.

\section{Methods}

Ethical approval was obtained from the institutional, Departmental Ethics Sub-Committee. Since there was no need for contact with patients, informed consent was not obtained. Confidential information was neither relevant nor necessary and so, it was avoided. This study was retrospective, cross-sectional and multiphase. Data collection was preceded by a physical inspection of radiology department for equipment and staffing as well as observation of workflow. The first stage of data collection was carried out in 2016 and involved assessment of radiographs stored in departmental physical archive. The radiographs were those generated between 2011 and 2013. The second stage of data collection was in 2019 and involved computed radiography (CR) images generated between 2015 and 2017 and stored on CR major workstation digital archive in the department.

Study location The study site is a government-owned teaching hospital. It was established in 1992 to serve as a referral hospital for a minimum population of about three million. Staff strength of $\geq 2500$ consists of clinical and non-clinical experts in different fields. However, majority of the staff are of non-clinical cadre. Personnel in Radiology Department were $\leq 120$ (5\%). The department was equipped with basic and moderately sophisticated imaging modalities and thus enjoyed medical tourism from contiguous states. It also served as a base teaching hospital for a department of radiography in one of the universities in the state, and for training residents in radiology. The radiology department had professional accreditation from Radiographers Registration Board of Nigeria (RRBN) for the training of interns and from the Postgraduate Medical Colleges for the training of residents. Those interns and residents also constitute the workforce.

Equipment The diagnostic x-ray equipment in the department used in producing the bulk of images under study using CR and film-screen radiography were two General Electrics (GE) silhouette VR, high frequency, 3phase, static $\mathrm{x}$-ray machines with maximum rating of $140 \mathrm{kVp}$ (tube potential), $600 \mathrm{~mA}$ (tube current) and 2.7 $\mathrm{mm} \mathrm{Al} \mathrm{(total} \mathrm{filtration)} \mathrm{manufactured} \mathrm{in} 2003$ and installed in 2012. The undercouch and erect potter-bucky 
trays were functional. Other equipment and accessories were a computed radiography digitizer, model CR 12-x, produced in December 2013 by Agfa healthcare Belgium. A $25 \mathrm{~cm} \times 30 \mathrm{~cm}\left(10^{\prime \prime} \times 12^{\prime \prime}\right)$ and $35 \mathrm{~cm} \times$ $43 \mathrm{~cm}\left(14^{\prime \prime} \times 17^{\prime \prime}\right)$ standard photostimulable phosphor imaging plates (model CR MD4.0T General) also produced by Agfa Healthcare Germany were available. The $\mathrm{CR}$ system was linked to the $\mathrm{x}$-ray machines in October, 2014.

Procedure All radiographs and CR images generated in the department were documented. However, some of the radiographs were not available due to the inability of the patients to return them after seeing their physicians in the clinic. All returned remaining $x$-ray images (radiographs) enclosed within physical folders in departmental archive were studied. Folders were checked and classified into years in which examinations were done. Subsequently, those with dates bearing 2012 to 2014 were selected. From that pool, radiographs which had deteriorated due to molds, discoloration, cardboard sticking and dirt were excluded. The balance was checked for marker presence, and their location (within $\mathrm{x}$-ray beam umbra or penumbra) (Figs. 1 and 2). Data capture sheet was used for data collection. Equal number of FSR and $\mathrm{CR}$ images were studied for ease of comparison.

For CR, electronic folders were arranged in descending order of date of generation. Each folder generated between 2015 and 2017 were consecutively scrutinized. Deleted images which were digitally marked ' $x$ ' to indicate reject but still remained on workstation for reference purpose were also scrutinized to assess if they were rejected due to marker error. Specific errors sought were presence or absence of markers, and legibility. Data collection for CR was halted when sample size previously adopted from FSR had been attained. Confidentiality was maintained throughout the duration of the study.

Data analysis Data collected were manually counted, subjected to descriptive statistics and presented in figures and percentages. Percentage difference was calculated using simple calculator.

\section{Results}

From Table 1, a total of 72,602 radiographs and 126,482 electronic images were documented for FSR and CR, respectively in the department. From those populations, a sample size of 9452 made up of 4726 each for FSR and $\mathrm{CR}$ was collected. Anatomical side marker errors were common in every anatomy imaged (Table 2), with more errors seen in FSR (4.6\%) than CR (0.6\%). Collectively, an error rate of $3.0 \%$ was observed (Table 3). Table 4 shows a comparison of errors from our study with similar works in the literature. ASMs error was present in

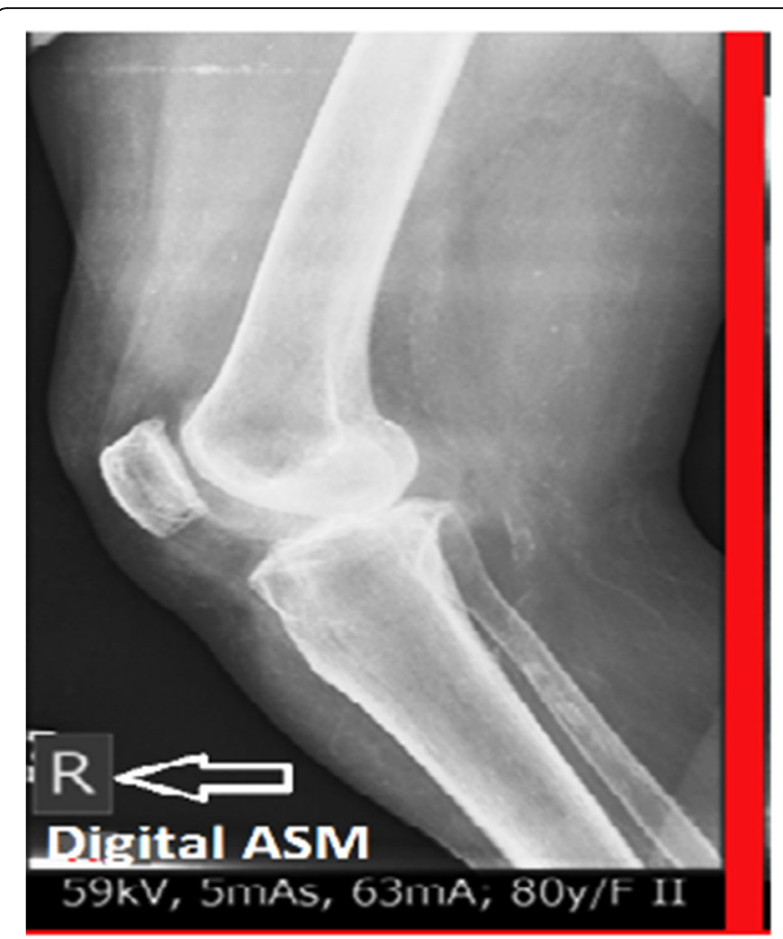

Fig. 1 Knee image with digital marker

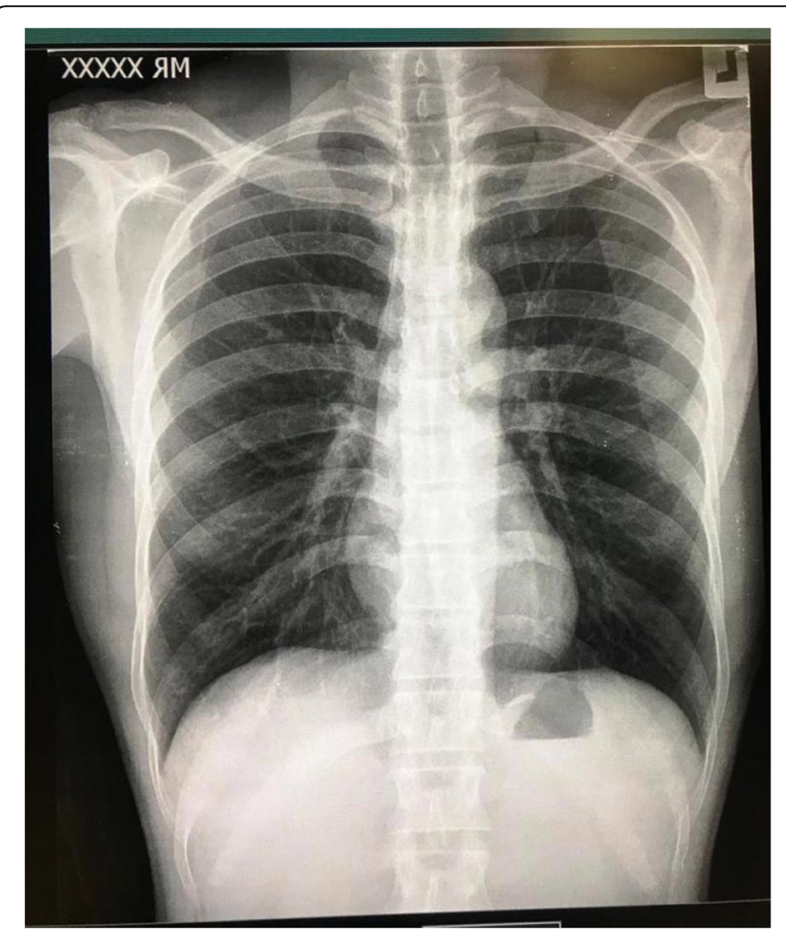

Fig. 2 Radiopaque marker on chest radiograph 
Table 1 Average annual population of $x$-ray images and sample size for the study

\begin{tabular}{|c|c|c|c|c|c|c|c|}
\hline \multirow[t]{2}{*}{ Image technology era } & \multirow[t]{2}{*}{ Year(s) } & \multicolumn{2}{|l|}{ Adults } & \multicolumn{2}{|c|}{ Paediatrics } & \multirow[t]{2}{*}{ Total } & \multirow{2}{*}{$\begin{array}{l}n \text { (images } \\
\text { scrutinized) }\end{array}$} \\
\hline & & Male & $\overline{\text { Female }}$ & Male & $\overline{\text { Female }}$ & & \\
\hline Pre-CR installation (FSR) & $2011-2013$ & 27,584 & 34,844 & 4,355 & 5819 & 72,602 & 4726 \\
\hline Post-CR installation (CR) & $2015-2017$ & 52,660 & 52,976 & 12,423 & 8423 & 126,482 & 4726 \\
\hline Total (mean) & $2011-2017$ & 40,122 & 43,910 & 8389 & 7121 & 99,542 & 9452 \\
\hline
\end{tabular}

radiographic images in all the studies. However, zero error rate was observed in one of the studies of digital images (Table 4). Figures 3, 4, 5 and 6 showed the personnel in relation to modalities, categories of personnel in the department, available modalities, positions of ASMs and radiographs of the knee joint, and chest showing anatomical side marker.

\section{Discussion}

Errors in radiographic image annotation by radiographers could potentially lead to misdiagnoses by radiologists and wrong side surgery by surgeons. Such medical negligence has dire medico-legal consequences [7]. It was hypothesized that image annotation with newer technology of CR and direct digital radiography (DDR) would potentially lead to a change in practice with subsequent reduction in annotation errors [1]. Following installation of computed tomography, a modality with electronic image annotation, the hypothesis was investigated in our study centre. The choice of study centre was due to its reputation of being well-equipped with different radiological modalities as well as being wellstaffed with both quality and quantity of radiation personnel (Figs. 3, 4, and 5).

Findings from our study showed considerable reduction in annotation errors between FSR (4.6\%) and CR $(0.6 \%)$. That was a $670 \%$ decrease in error when FSR is compared with CR. Our $0.6 \%$ error rate in CR is closely similar to that of Platt and Strudwck [1], who recorded zero error in CR images. However, Barry et al. [6] recorded higher values of error (5.8\%) in similar study in Australia. The possible reason for the variation may be attributable to the methodology. While our study

Table 2 Anatomy-specific location of ASM on images

\begin{tabular}{llll}
\hline Anatomical region & Marker presence & Marker error (\%) & Total $(\boldsymbol{n})$ \\
\hline Chest & 3656 & 12 & 3668 \\
Abdomen & 1844 & 8 & 1852 \\
Lower Limb & 1224 & 168 & 1392 \\
Neck & 864 & 8 & 872 \\
Upper Limb & 581 & 25 & 606 \\
Pelvis & 534 & 14 & 548 \\
Head & 509 & 7 & 514 \\
Total & $9212(97.0 \%)$ & $242(3.0 \%)$ & 9452 \\
\hline
\end{tabular}

evaluated CR images in a general imaging department acquired over several weeks, that of Barry et al. (2016) evaluated images generated over a period of $48 \mathrm{~h}$ in a paediatric department. It is therefore our opinion that CR and DDR images could reduce or completely eliminate errors in image annotations in medical imaging. Anecdotal evidence from observation of radiographers at work in the study centre revealed their meticulous efforts to eliminate error from radiographic procedures. Errors which inadvertently crept in were mainly due to marker burnout from overexposure, and cone-off, due to ambitious collimation.

It was reported that zero error level was possible if a checklist used in the quality control room contains presence or absence of anatomic side maker as a fundamental item. Our study showed that $43 \%$ of the marker positions were in the umbra region of the radiation similar to other studies that recorded $25-32 \%$ placement in the same region $[1,6]$. This is however contrary to the recommendations of Platt and Strudwick [1] and Bontrager and Lampignano [9] who advocated 100\% marker placement in the umbra region of the radiation beam. An earlier study in our centre almost aligned with the recommendation, as $89 \%$ of markers was placed in umbra region [4]. That study evaluated only FSR in contrast to the present study which evaluated both FSR and $\mathrm{CR}$. The CR was a probable cause of reduction in errors.

We observed that marker placement within umbra of the x-ray beam, aside from being a practice of precedent, did not appear to offer any superior advantage to markers placed within the penumbra. A growing global tendency of radiographic image annotation within penumbra calls for a re-evaluation of the old order [3]. In view of the evidence from our present study and from literature, we suggest that the best practice of ASM should be guided primarily by legibility and sparing of essential anatomy and secondly by aesthetics.

Table 3 Error rates in film-screen radiography and computed radiography

\begin{tabular}{llll}
\hline Parameter & FSR & CR & Total \\
\hline Sample size $(n)$ & 4726 & 4726 & 9452 \\
Images annotated & 4511 & 4699 & 9212 \\
& $(95.4 \%)$ & $(99.4 \%)$ & $(97.0 \%)$ \\
$\begin{array}{l}\text { Images with improper } \\
\text { annotation }\end{array}$ & $215(4.6 \%)$ & $27(0.6 \%)$ & $242(3.0 \%)$ \\
\hline
\end{tabular}


Table 4 Comparison of error rate with similar works

\begin{tabular}{llllll}
\hline Region & Location & Year & Technology & $\begin{array}{l}\boldsymbol{n} \\
\text { error }\end{array}$ \\
\hline Present work & Nigeria & 2020 & CR & 4726 & 0.6 \\
& Nigeria & 2020 & FSR & 4726 & 4.51 \\
Adejoh et. al. [4] & Nigeria & 2014 & FSR & 623 & 2.0 \\
Attard et. al. [3] & Malta & 2016 & FSR & 500 & 14 \\
Barry et. al. [6] & Australia & 2016 & Digital & 400 & 5.8 \\
Platt and Strudwick & UK & 2004 & FSR & 100 & 1.0 \\
2008 [1] & UK & 2006 & Digital & 100 & 0 \\
Aakre and Johnson [12] & Unknown & 2006 & FSR & 2536 & 2.4
\end{tabular}

Although ASM error of $0.6 \%$ was observed with CR in comparison to $4.51 \%$ of FSR in our study, the more reliable result ought to be from FSR. This is because FSR involves pre-exposure marker placement, rather than post-exposure where there is possibility of marker position modifications. Adding markers during postprocessing is considered a sloppy method which only encourages error [10]. Notwithstanding, it is reported that in ASM error analysis, a higher error rate is to be expected from FSR than with CR [11]. Since no study has shown zero error rate with FSR, the observation that incorrect use of pre-exposure ASMs is one of the major sources of error in radiography could be justified [12]. The 2\% error rate in FSR of an earlier study [4] and $4.6 \%$ (FSR) of the present study is in the same range of 2.4\% reported by Aakre and Johnson (2006) [12].

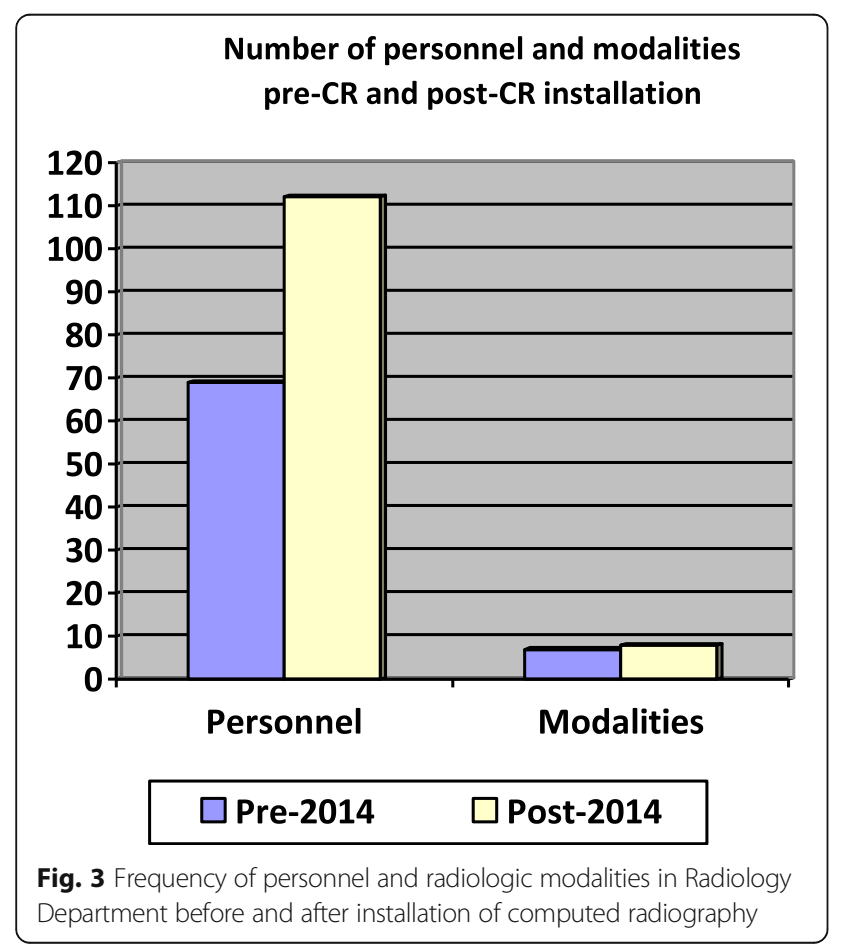

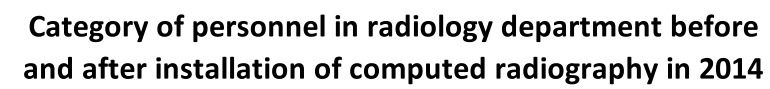

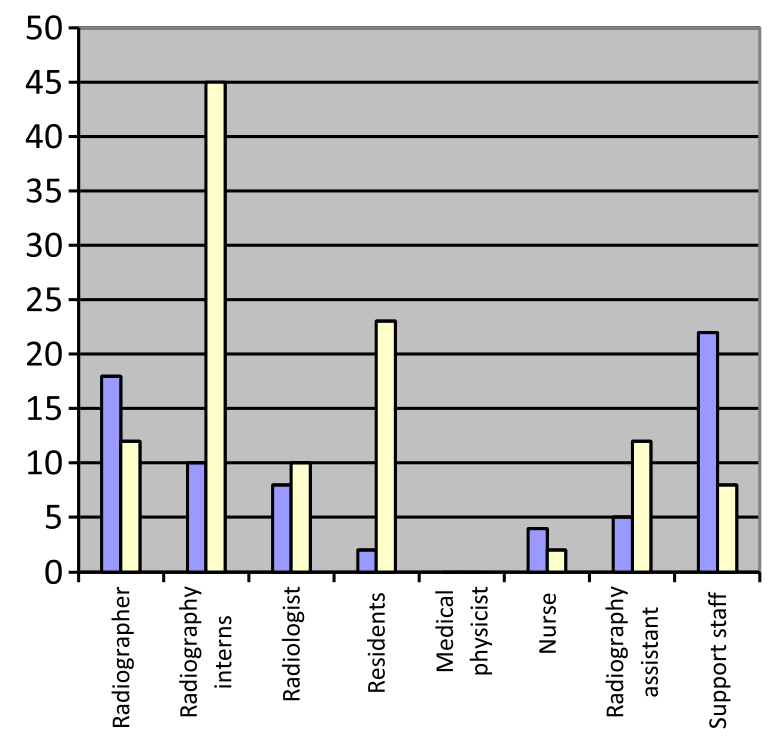

\section{$\square$ Pre-CR $\quad \square$ Post-CR}

Fig. 4 Compound bar chart of categories of personnel found in the department
Available equipment in radiology department from 2011 - 2018

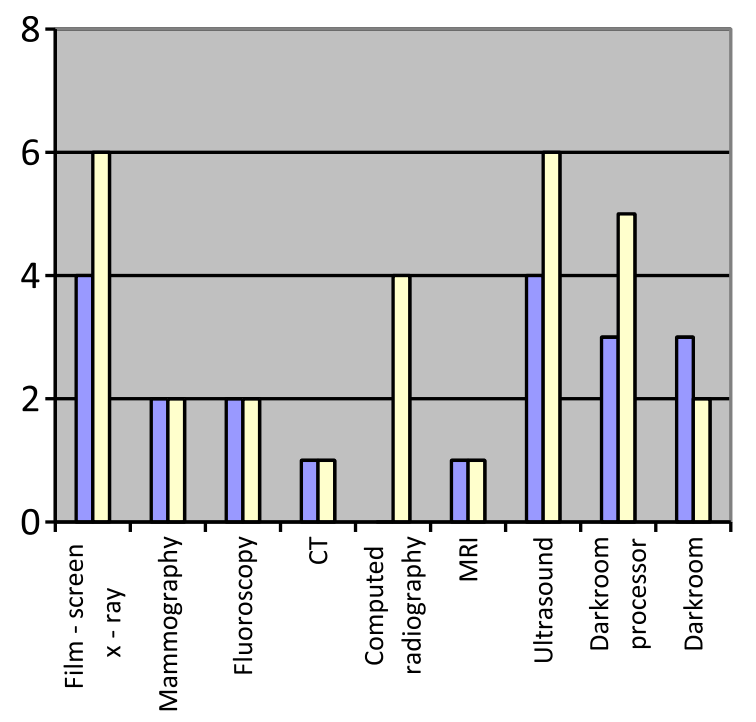

\section{$\square$ Pre-CR $\square$ Post-CR}

Fig. 5 Compound bar chart of modalities and equipment available for radiographic imaging 


\section{Location of anatomical side markers in radiation field}

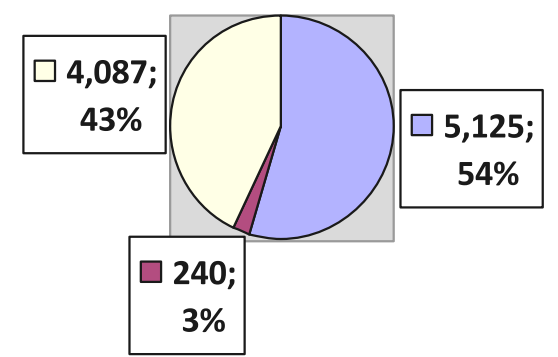

\section{Penumbra $\square$ Error $\square$ Umbra}

Fig. 6 Pie chart of anatomical marker locations within radiation beam

Annotation error, however, increased in the present study by $126 \%$. The difference may be due to sampling technique applied in the studies. Whereas, simple random sampling $(n=623)$ was adopted in the older study, complete enumeration $(N=4726)$ was adopted in the current study. Error rate would be more accurate with complete enumeration since every data would benefit from analysis. The fact that higher error persisted with FSR in the centre calls for further research with anthropomorphic phantoms in order to perfect preexposure marker placement. The authors are of the strong opinion that consistent practice with anthropomorphic phantoms, rather than patients, is a necessary first step in eliminating errors in imaging, especially where students are being trained.

Following installation of $\mathrm{CR}$ and acquisition of additional equipment, there was consequent increase in the number of personnel by as much as $62.3 \%$. This appeared to be an administrative strategy to ensure that resources were appropriately managed. Experienced radiographers however, decreased from $\leq 18$ to $\leq 12$ while interns who were their mentees increased from $\leq$ 10 to $\geq 45$ (350\%). Radiography Interns, after a month or less of orientation, are usually in the frontline of image generation. An investigation of radiographic image annotation with ASMs by hospitals that train interns is indirectly a quality control of the practice of those interns, and directly an assessment of the effectiveness of supervision by senior radiographers. Although the overall $0.6 \%$ error rate in $\mathrm{CR}$ appears commendable, a zero error rate should be the goal. This is likely if interns are not left to work unsupervised soon after assumption of duty. They ought to acclimatize with equipment and accessories to reduce marker burnout and cone-off which constituted the errors at the centre.
As has been observed both from our work and in the literature, error rate was higher in FSR than in computed radiography. There are plausible explanations for this. Whereas FSR and CR always undergo pre-exposure marking, only CR enjoys the privilege of another round of post-exposure marking. Post-exposure marking on FSR is a patently slobby practice that should be discouraged and is often counted as error during marker audits [10]. The higher error rate in FSR may be due to the ease with which pre-exposure markers are identifiable from post-exposure markers using aesthetics. Postexposure marking in FSR is not as aesthetic as in preexposure. If re-irradiation is used, re-exposed area will appear darker than surrounding areas of the image due to further activation of silver halide and deposition of black metallic silver in the film emulsion. If scratching or pen marking is used, it will appear on, and not, in the image. In CR however, radiographers can easily mask errors of absence of marker by revisiting previous images. The authors are therefore of the opinion that the most reliable error rate in any marker audit are those from FSR where error masking is easily detectable.

From anecdotal experience, in busy departments with very few radiopaque markers, radiographers tend to use radiopaque object such as syringe needles to indicate an anatomical side with the intention of later using an electronic marker to mask it. Many times, such needles fall off, are displaced outside radiation beam or become illegible due to beam attenuation by obese patients. Solution to marker errors should incorporate anthropomorphic phantoms and abundance of radiopaque markers in the department. While a single anthropomorphic phantom may be adequate for the whole department, each radiographer should possibly own a personal marker. Furthermore, pre-exposure markers become illegible when obese patients attenuate radiation beam. Imaging of the obese patient presents diagnostic challenges that have appeared insurmountable over the years [13]. The fixed nature of detector casing sizes makes this problem difficult to address. The largest size of detector casing in use in our country is 14 in $\times 17$ in $(35 \mathrm{~cm} \times 43 \mathrm{~cm})$. Abdomen and pelvis for some obese patients extend beyond the edges of this size of casing and provide no free space for marker placement. The solution may lie with cassette manufacturers. If they will produce obese-specific detector casing sizes, illegibility and cone-off of markers may reduce.

Our work had some limitations. Due to the retrospective nature of data collection, it was not possible to ascertain if the $0.6 \%$ error rate in computed radiography actually represented excellent pre-exposure ASM placement or post-exposure annotation 'excellence' at workstation. A prospective work to clearly ascertain this is therefore envisaged in the near future. 


\section{Conclusions}

In conclusion, error rates were considerably reduced following a change from film-screen radiography (FSR) to computed radiography (CR) at the study centre. This change was however influenced more by a team of quality control radiographers stationed at CR workstation than by actual practice in $\mathrm{x}$-ray imaging suite. If this positive change is to be sustained however, there should be quality control charts to track progress. In addition, presence of anthropomorphic phantoms in demonstration suites in the universities and abundance of ASMs in the hospitals will significantly inculcate the skill needed to completely eliminate ASM error in practice.

\section{Abbreviations}

ASM: Anatomical side marker; CR: Computed radiography; FSR: Film-screen radiography; GE: General Electrics; L-R: Left-Right; mm Al: Millimeter of Aluminum; mA: Milliampere; kVp: Peak kilovoltage

\section{Acknowledgements}

Authors would wish to acknowledge the efforts of Mrs. Nwamaka C. Ikegwuonu (M.Sc Medical Imaging), who was Head of Radiography Section at Nnamdi Azikiwe University Teaching Hospital, Nnewi, Nigeria, for her unpublished pilot study on marker error which became a stimulus for our study.

\section{Authors' contributions}

TA designed the study, co-collected, and analyzed data. CHE collected data. MS, EEE, COA and MCO reviewed the work. All six authors have read and approved the manuscript.

\section{Funding}

None.

\section{Availability of data and materials}

The data sets used and/or analyzed during the current study are available from the corresponding author on reasonable request.

\section{Ethics approval and consent to participate}

Ethical approval was obtained from the Radiology Department Research Ethics Subcommittee of Nnamdi Azikiwe University Teaching Hospital, Nnewi, Nigeria (RAD/EZ/ETH/002/2016).

\section{Consent for publication}

Not applicable.

\section{Competing interests}

The authors declare that they have no competing interests.

\section{Author details}

${ }^{1}$ Department of Radiography \& Radiation Sciences, Gregory University, Uturu, Abia State, Nigeria. ${ }^{2}$ Department of Medical Radiography, Bayero University, Kano, Nigeria. ${ }^{3}$ Department of Radiography \& Radiological Sciences, Nnamdi Azikiwe University, Awka, Nigeria. ${ }^{4}$ Department of Radiography \& Radiological Sciences, University of Nigeria, Nsukka, Nigeria.

Received: 8 October 2020 Accepted: 25 November 2020

Published online: 08 December 2020

\section{References}

1. Platt JM, Strudwick RM (2009) The application of anatomical side markers during abdominal and IVU examinations: An investigation of practice prior to and post-installation of computed radiography (CR). Radiography 15(4): 292-299. https://doi.org/10.1016/j.radi.2008.11.006

2. Murphy A, Ekpo E, Steffens T, Neep MJ (2019) Radiographic image interpretation by Australian radiographers: a systematic review. J Med Radiat Sci 000:1-15. https://doi.org/10.1002/jmrs.356
3. Attard S, Couto JG, Mackay S, Zarb F (2017) Anatomic site markers: evaluation of their use among maltese radiographers. J Med Imaging Radiat Sci 48(1):30-38. https://doi.org/10.1016/j.jmir.2016.08.006

4. Adejoh T, Onwuzu SWO, Nkubli FB, Ikegwuonu NC (2014) Radiation field preference for radiographic anatomical markers by radiographers in a university Teaching hospital in Nigeria. Open J Radiol 4:275-227. https://doi. org/10.4236/ojrad.2014.43036

5. Tugwell J, Maddison A (2011) Radiographic markers-a reservoir for bacteria? Radiography, 17(2), 115-120. DOI. https://doi.org/10.1016/j.radi. 2010.10.005

6. Barry K, Kumar S, Linke R, Dawes E (2016) A clinical audit of anatomical side marker use in a paediatric medical imaging department. J Med Radiat Sci. 63(3):148-154. https://doi.org/10.1002/jmrs.176

7. Davis M, Reeves P (2004) Maintaining the chain of evidence in child abuse cases. J Diagn Radiol Imaging 5:61-68. https://doi.org/10.1017/ S1460472804000021

8. Titley AG, Cosson P (2014) Radiographer use of anatomical side markers and the latent conditions affecting their use in practice. Radiography 20:42-47. https://doi.org/10.1016/j.radi.2013.10.004

9. Bontrager $\mathrm{KL}$, Lampignano JP (2010) Textbook of radiographic positioning and related anatomy, 7th edn. Mosby Elsevier, Maryland Heights

10. Ball J, Price T (1995) Chesneys' radiographic imaging, 6th edn. Blackwell, Oxford

11. Lau S, Mak AS, Lam W, Chau C, Lau K (2004) Reject analysis: a comparison of conventional film-screen radiography and computed radiography with PACS. Radiography 10:183-187

12. Aakre KT, Johnson CD (2006) Plain-radiographic image labeling: a process to improve clinical outcomes. J. Am. Coll. Radiol. 3:949-953. https://doi.org/10. 1016/j.jacr.2006.07.005

13. Thanh Le NT, Robinson J, Lewis SJ (2015) Obese patients and radiography literature: what do we know about a big issue? J Med Radiat Sci 62(2):132141. https://doi.org/10.1002/jmrs.105

\section{Publisher's Note}

Springer Nature remains neutral with regard to jurisdictional claims in published maps and institutional affiliations.

\section{Submit your manuscript to a SpringerOpen ${ }^{\circ}$ journal and benefit from:}

- Convenient online submission

- Rigorous peer review

- Open access: articles freely available online

High visibility within the field

- Retaining the copyright to your article

Submit your next manuscript at $>$ springeropen.com 